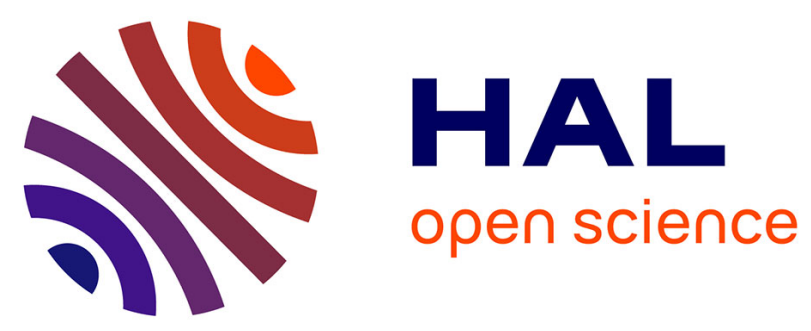

\title{
An experiment-based method for parameter identification of a reduced multiscale parametric viscoelastic model of a laminated composite beam
}

Gilberto Fontecha Dulcey, Xavier Fischer, Pierre Joyot

\section{- To cite this version:}

Gilberto Fontecha Dulcey, Xavier Fischer, Pierre Joyot. An experiment-based method for parameter identification of a reduced multiscale parametric viscoelastic model of a laminated composite beam. Multiscale and Multidisciplinary Modeling, Experiments and Design, 2018, 1 (4), pp. 291 - 305. 10.1007/s41939-018-0018-8 . hal-01929122

\section{HAL Id: hal-01929122 \\ https://hal.science/hal-01929122}

Submitted on 13 Mar 2019

HAL is a multi-disciplinary open access archive for the deposit and dissemination of scientific research documents, whether they are published or not. The documents may come from teaching and research institutions in France or abroad, or from public or private research centers.
L'archive ouverte pluridisciplinaire HAL, est destinée au dépôt et à la diffusion de documents scientifiques de niveau recherche, publiés ou non, émanant des établissements d'enseignement et de recherche français ou étrangers, des laboratoires publics ou privés. 


\title{
An experiment-based method for parameter identification of a reduced multiscale parametric viscoelastic model of a laminated composite beam
}

\author{
Gilberto Fontecha Dulcey ${ }^{1,2} \cdot$ Xavier Fischer $^{2,3}$ (1) $\cdot$ Pierre Joyot $^{2,3}$
}

Received: 16 May 2018 / Accepted: 5 June 2018 / Published online: 22 June 2018

c) Springer International Publishing AG, part of Springer Nature 2018

\begin{abstract}
Usual CAE tools simulate the behavior of composite parts from models considering the structures as being homogenized. Such approach reveals itself not to be effective when the engineer aims at determining the number of plies and the material characteristics of each ply to aim a specific dynamic behavior. To reply to this problem, we developed a multi-scale model that explicitly integrates the different design parameters of the composite structure being considered at different scales: the number of plies, the orthotropic law of each ply and the characteristics of each interface between the plies made by the matrix. This paper is detailing the method that we developed to lead to our multi-scale and parametric model. This method is coupled to an experimental approach that allows specific variables named fractional variables to be identified. These variables add to the detailed representation of the dynamic capacities of the laminated composite beams that led our study. In the case of our composite beams, the effect of damping due to the ply-interface behavior is significant, and consequently we dealt with the viscoelastic response of the laminated composite beam under dynamic load. As a result, the strategy of simulation based on our reduced, viscoelastic and multi-scale beam model is presented: solutions with low computational resources may be obtained.
\end{abstract}

Keywords Fast simulation for CAE · Reduced model $\cdot$ Multi-scale model $\cdot$ viscoelastic behavior $\cdot$ Model parametrization . Method based on numerical and experimental approach

\section{List of symbols}

$\begin{array}{ll}E & \text { Young's modulus }(\mathrm{MPa}) \\ G & \text { Shear modulus }=G_{0}(\mathrm{MPa}) \\ v & \text { Poisson's ratio } \\ l & \text { Beam length }(\mathrm{m}) \\ h & \text { Beam height }(\mathrm{m}) \\ w & \text { Beam width }(\mathrm{m}) \\ u & \text { Direction } x\end{array}$

Xavier Fischer

x.fischer@estia.fr

Gilberto Fontecha Dulcey

gilberto.fontecha@upb.edu.co

Pierre Joyot

p.joyot@estia.fr

1 Universidad Pontificia Bolivariana, $\mathrm{Km} 7$, Autopista Piedecuesta, Bucaramanga, Colombia

2 I2M CNRS UMR 5295, Université de Bordeaux, ENSAM, Esplanade des Arts et Métiers, 33400 Talence, France

3 ESTIA, Technopôle Izarbel, 64210 Bidart, France $v \quad$ Direction $y$

$w \quad$ Direction $z$

$\varepsilon \quad$ Strain tensor

$\sigma \quad$ Stress tensor (MPa)

$\sigma_{i j} \quad$ Stress tensor element (MPa)

$U \quad$ Displacement field (m)

$H \quad$ Tensor of material properties

$B \quad$ Body forces (N)

$R \quad$ External forces $(\mathrm{N})$

$\tau \quad$ Relaxation time (s)

$G_{\infty} \quad$ Long-term shear modulus (Mpa)

$\alpha \quad$ Fractional order of a derivative

$\eta \quad$ Loss factor

$u^{*} \quad$ Test function

$\Omega \quad$ Continuous domain

$\Gamma \quad$ Continuous boundary domain

$X \quad$ PGD function in $x$ domain (in-plane)

$Y \quad$ PGD function in $y$ domain (transverse)

$D \quad$ PGD function in $d$ domain used for parametrization of $G_{\infty}$ 
A PGD Function in $a$ domain used for Parametrization of the fractional derivative order $\alpha$

$Q \quad$ PGD function for properties change $q$

$S, P \quad$ PGD function for ply orientation change $\theta$

$M \quad$ PGD function for number of plies $m$

\section{Introduction}

Laminated composite materials are mainly known to be used on applications where both a high strength and low density are required. But their benefits go far beyond these characteristics because it is also possible to obtain mechanical properties on demand, this means that it is possible to obtain a desired strength defining a given stacking sequence of layers whose maximum strength is oriented towards strategic directions. Further, due to the resin used as matrix and transferring the stresses to the fibers, these materials also exhibit a higher damping characteristics than the observed on metals, which results on a better capacity to dissipate vibrations (Galuppi and Royer-Carfagni 2012). These, and many other characteristics besides the mechanical ones, make laminated composites attractive to very critical structures where simulations are very important to predict their mechanical behaviors; however, the mismatch of properties between fibers and resin-producing localized strains makes important to be able to develop simulations not only at the highest scales to account for global deformations, but also in lower scales to develop advanced and optimized material properties or to understand the feasibility to develop a failure. This work presents the simulation of a laminated composite response under dynamic load, and considering viscoelasticity in the interfaces, the interest is to obtain a computationally light model representing the behavior of the lamination under a set of different mechanical properties, stacking sequences and number of plies.

\section{Case of study}

A laminated composite beam under dynamic load is studied in this work and it is restrained at one end and loaded at the other end as shown in Fig. 1. The lamination has eight unidirectional plies symmetrically stacked as [0, 90, 90, 0, 0, 90, 90, 0].

Ten samples of such a laminated composite beam were built all at the same time. They are made by eight prepreg unidirectional carbon fiber layers, coded as HexPly ${ }^{\circledR}$ M21/34\%/ UD200/T800S/150 mm. The resulting beams are shown in Fig. 2.

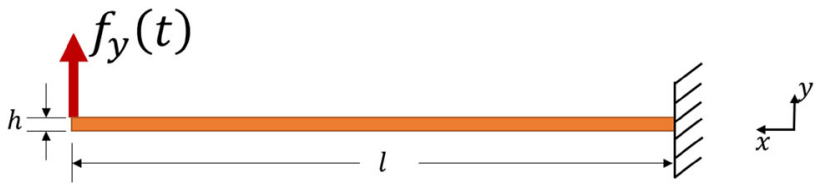

Fig. 1 Cantilever beam under study

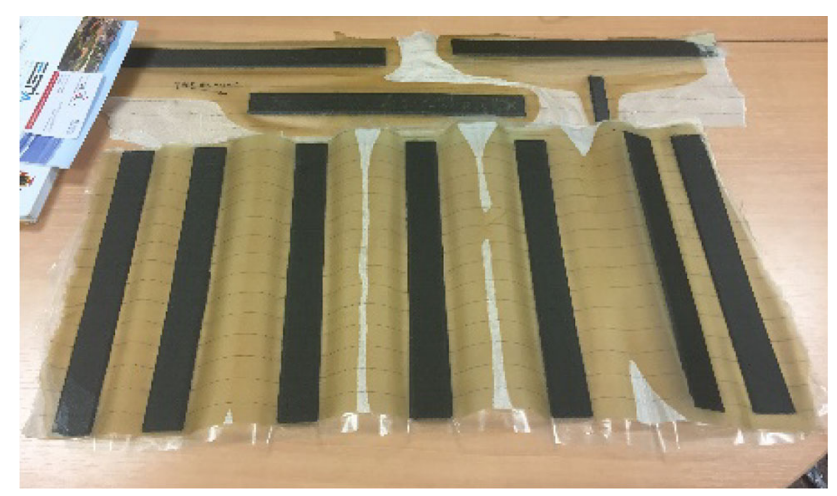

Fig. 2 Carbon fiber-laminated composite beams

\section{Significance of inter-ply viscoelastic behavior}

\subsection{Test setup}

The test setup is shown in Fig. 3 and carried out at a controlled temperature of $25 \pm 2{ }^{\circ} \mathrm{C}$. The frequency response functions were measured according to the procedure recommended by ISO 7626-2 (1990) using an electrodynamic shaker attached to the beams. The excitation force was measured with a force transducer PCB 208C01 installed between the shaker stinger and the free end of the bar, while three simultaneous responses were captured with a PCB 35C34 accelerometer mounted at the same position of the excitation and two other PCB 352C68 located at the beam midpoint and at the beam first quarter, respectively. The four sensors were carefully aligned in the center of the beams to diminish the influence of torsional modes on the responses and they connected to a simultaneous fourchannel data acquisition module NI 9234, and the data were gathered using LabVIEW ${ }^{\circledR}$. Figure 3 shows a detailed description of the location of sensors. The calibration of all the instrumentation and equipment used is regularly verified in accordance with an ISO 17025 accreditation granted to the lab.

\subsection{Demonstration of the damping behavior}

A visual inspection was conducted, so the test was performed with five of the most similar beams, and tested with the same procedure. Random vibration was then induced to each of the beams, with an approximated constant force of $1 \mathrm{~N}$ through 

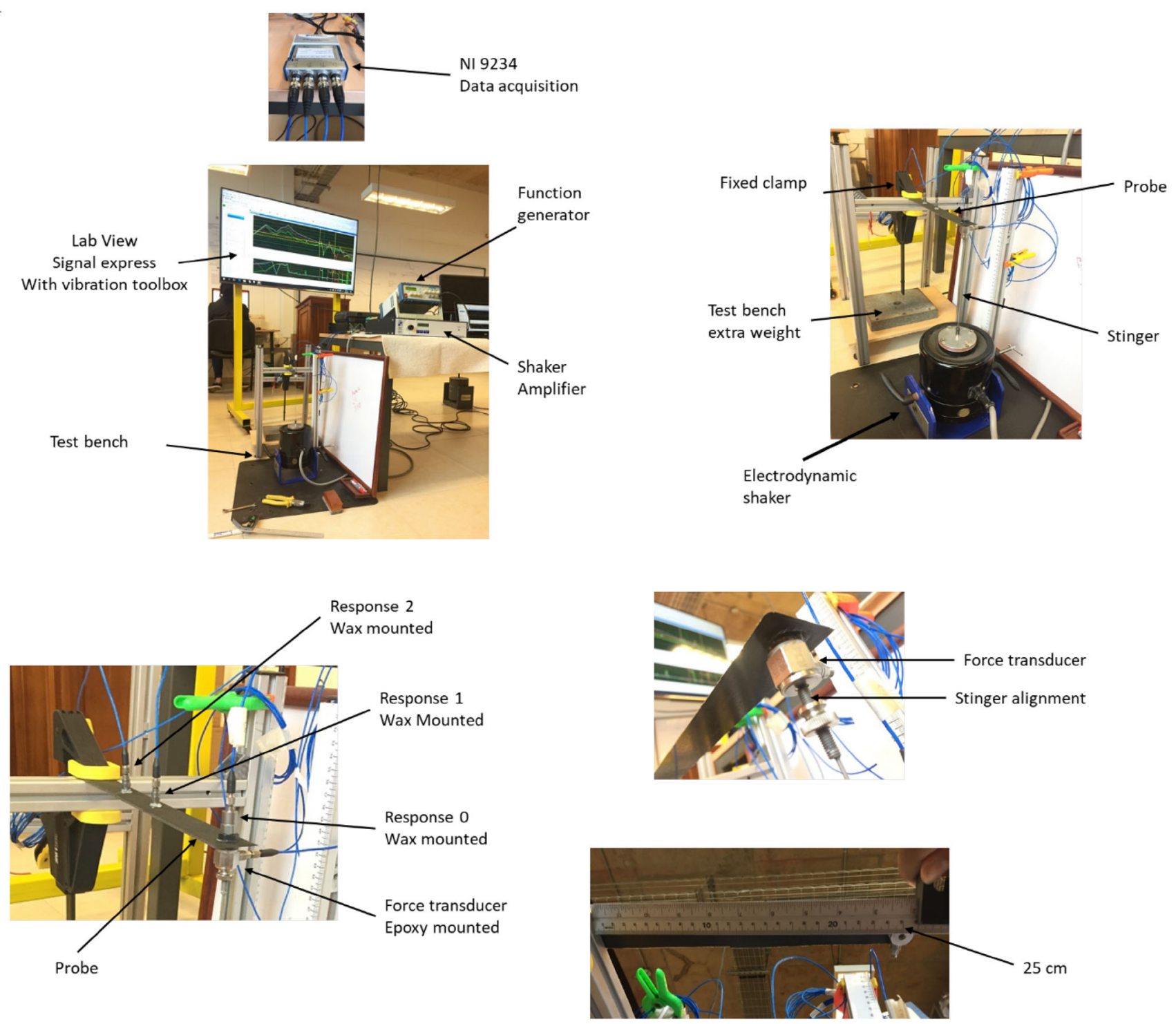

Fig. 3 Test setup

Table 1 Convention used to name the FRF's where $\omega$ is the angular frequency

\begin{tabular}{ll}
\hline Point FRF & $\frac{\text { Response } 0(\omega)}{\text { Excitationforce }(\omega)}$ \\
\hline Transfer FRF 1 & $\frac{\text { Response } 1(\omega)}{\text { Excitation force }(\omega)}$ \\
Transfer FRF 2 & $\frac{\text { Response } 2(\omega)}{\text { Excitation force }(\omega)}$ \\
\hline
\end{tabular}

a frequency span of $2000 \mathrm{~Hz}$. Three Frequency Response Functions were available for each beam, so along this work they are named according to the convention indicated in Table 1.

Three mobility FRFs at each beam were computed using single integration from the accelerometer signals and applying 50 linear vector averages. The results of every beams are also averaged and two of the most relevant mobility FRFs are plotted in Fig. 4. A first source of error is the sensor and wiring mass interference on the beams, this is why miniature sensors were installed in positions one and two, so the relationship between sensor to beam mass is 0.2 . Moreover, even if the instrumentation frequency response is good above $5 \mathrm{~Hz}$, from the coherence plots in Fig. 4 it is possible to check a roughly non-linear behavior below $11 \mathrm{~Hz}$, so this is a second limitation to the validity of the data which could be caused by the first resonance peak and some compliance in the clamp used to avoid producing damage in the beams, although still following a positive trend in the magnitude FRFs in this first low-frequency zone, meaning a spring characteristic typical of cantilever beams.

At a first glance, the identification of viscoelastic behavior in the beams is seen in Fig. 4 on the phase lag remaining 

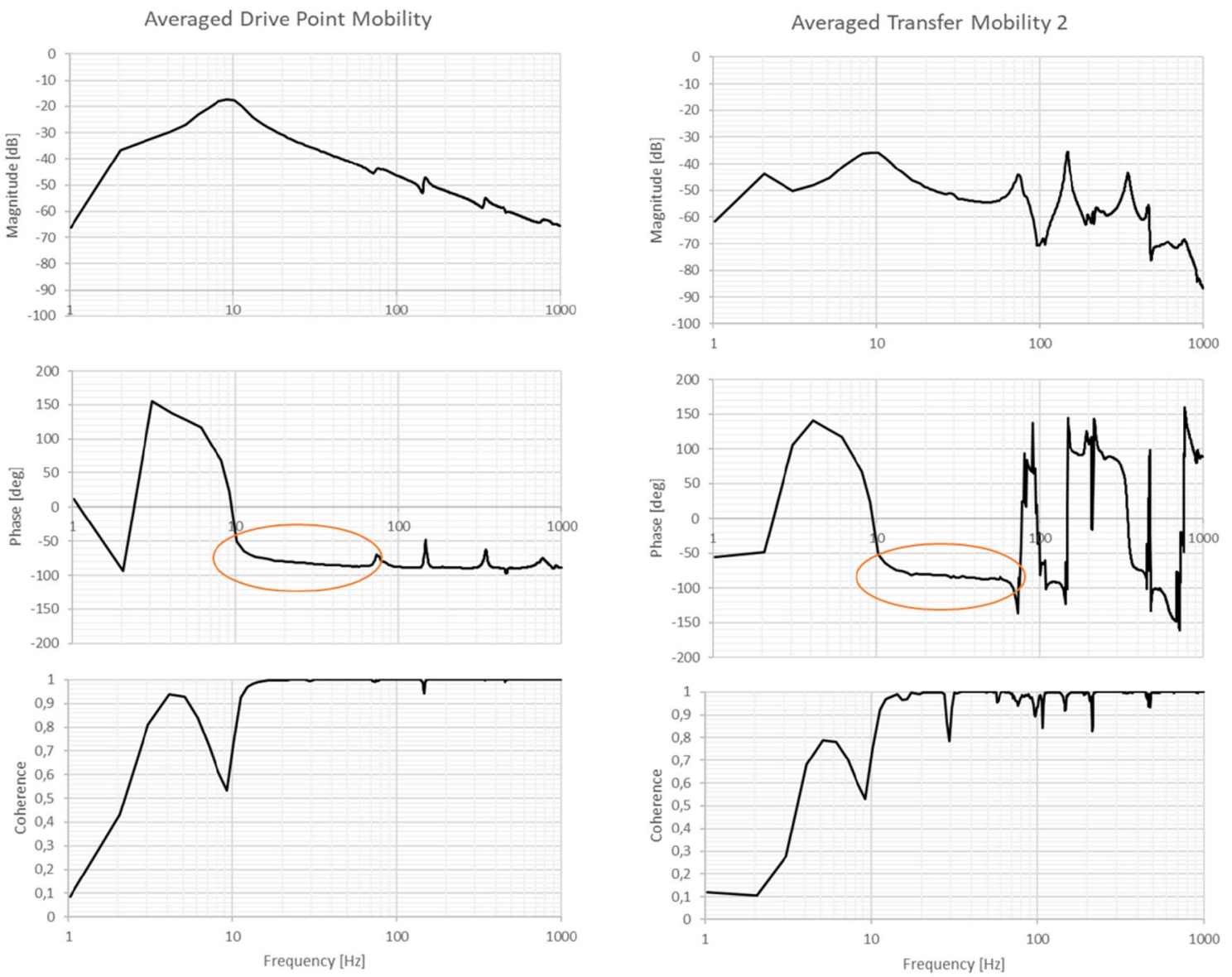

Fig. 4 Mobility FRF. Left: drive point. Right: transfer two. Highlighted is the phase lag caused by viscoelasticity

outside the natural frequencies, it is actually quite evident between 20 and $70 \mathrm{~Hz}$, bearing in mind that the coherence function in this zone is approximately one, indicating a good chance of linearity. Indeed, if no viscoelastic behavior was present there, the phase lag would be $90^{\circ}$, corresponding to pure elastic behavior between the velocity response and the force excitation. Then, an anti-resonance is identified at $72 \mathrm{~Hz}$, followed by a second longitudinal resonance peak at $77 \mathrm{~Hz}$. Besides, it is possible to identify torsional modes at 30 and $58 \mathrm{~Hz}$, but they are lightly excited due to the careful alignment of the sensors and excitation force along the center of the beams. Torsional modes are not considered along this work to simplify further simulations under $2 \mathrm{D}$ plane strain assumption.

Taking into account from the above, in Fig. 5 the stiffness magnitude and phase are plotted for a narrower frequency span where the best data quality is found in terms of linear response and the viscoelastic behavior to simulate further on, specifically because the long-term mechanical property is expected to be higher than the static property and the phase shift as function of frequency.

\section{A modelling method based on a combined numerical versus experimental approach}

\subsection{Fundamental basis of the multi-scale and viscoelastic model}

We aim to model the response of a laminated composite beam under dynamic load, considering pure elastic response within the fibers and a viscoelastic behavior in the interfaces, so that the detailed stress and strain through the thickness direction may be analyzed at different material properties, ply orientation and number of plies.

This makes the equivalent single-layer theories (ESL) exposed by Reddy (1993) out of the options, although they offer good overall accuracy especially using high-order theories (Li et al. 2014) or zero-order theories (Datta and Ray 2016), they fail representing the stress field detail through the thickness direction. Layer-wise approaches as used by Robbins et al. (2005) or as the ones presented in Carrera (2002) might be a good choice, particularly in this work, the author uses fictitious thin layers to introduce interfacial effects to model imperfect bonding between plies, obtain- 

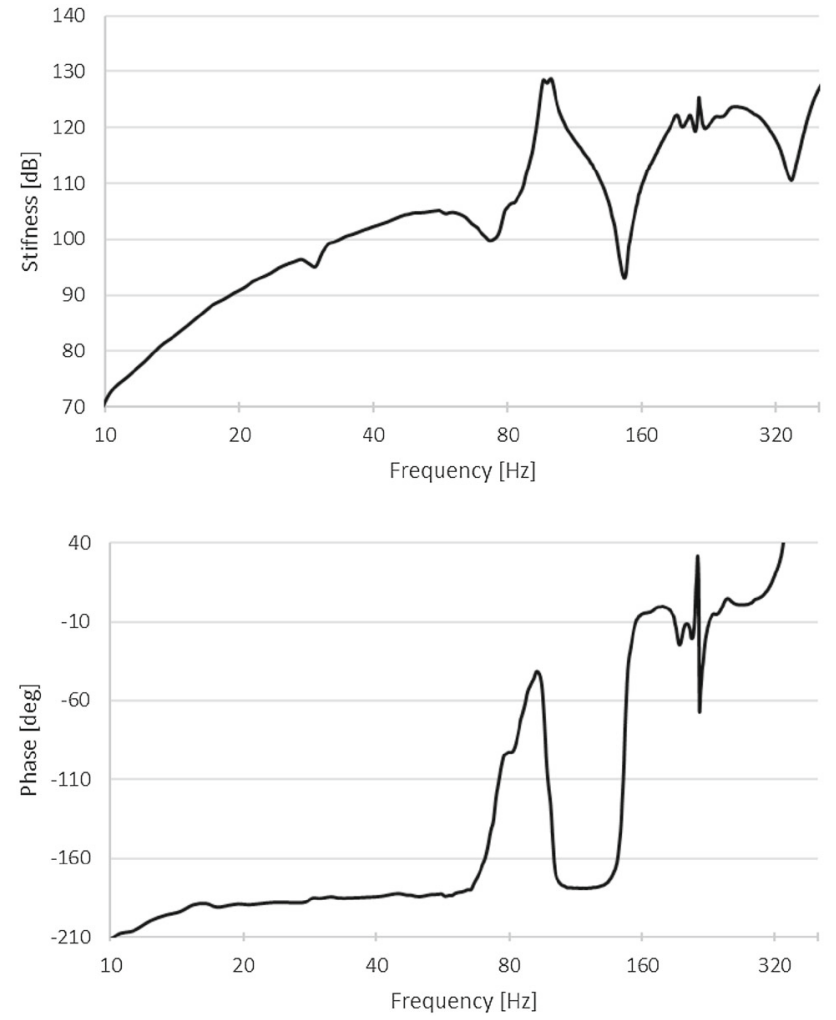

Fig. 5 Stiffness magnitude and phase for FRF two

ing accuracy improvements, although even if in Carrera and Ciuffreda (2005) the authors propose a unified formulation to assess theories, a designer still has to deal with choosing along a complex and wide diversity of models in advance to perform a simulation.

Within this scenario, the only option is to fully model the behavior through the thickness direction and obtain a solution by the finite element method (FEM) (Budiman et al. 2015; Liu et al. 2016), but new terms are added to the equations and very fine meshes are required, thus the computational cost and time is high.

Venkatachalam and Balasivanandha Prabu (2012), and Sahoo and Ray (2017) highlighted the relevance of viscoelastic properties of a composite part. However, the main problem is that simulation costs are important. Yet in 2006, Lisandrin and Tooren (2006) aimed at making lower computing costs by reducing a dynamic model of a composite beam. This position matches with our objective.

Therefore, an alternative reduced model is desired, providing full 3D modelling so no previous assumption theories are requested to the user, yet at a reasonable computational cost and time. In this sense, the proper generalized decomposition (PGD) has been used to provide those characteristics all together (Chinesta et al. 2014). The validation of the PGD method used hereby has been presented extensively (Ammar et al. 2015; Bognet et al. 2012; Ghnatios et al. 2016) and the application to a detailed through the thickness model and parametrization has been presented in a previous work for the same beam but under static load.

Finally, the PGD method is also used to construct a new model by parametrization of key variables, this is the most remarkable and interesting characteristic because the resulting model requires low computing cost to obtain a solution within seconds, thus a potential application to optimization purposes.

In the case of the laminate used in this work with multiples bodies $i$ interacting between each other, the principle of conservation of linear momentum defines the kinetics of the problem by the internal forces, inertia and body forces,

$$
\sum_{i=0}^{n} \nabla \cdot \sigma^{i}+\sum_{i=0}^{n} \rho \frac{\partial^{2} U}{\partial t^{2}}=B
$$

Assuming that the displacement gradients are sufficiently small, the kinematics relating to strain and displacement is defined by,

$\boldsymbol{\varepsilon}^{i}(U)=\frac{1}{2}\left(\nabla U^{i}+\left(\nabla U^{i}\right)^{T}\right)$

So by the Hamilton's principle the governing equations is,

$$
\begin{gathered}
\int_{\Omega} \sigma^{i}: \varepsilon^{i}\left(u^{*}\right) \cdot d \Omega \cdot d t-\rho \int_{\Omega} \frac{\partial^{2} U^{i}}{\partial t^{2}} \cdot u^{*} \cdot d \Omega \cdot d t \\
=\int_{\Omega} B \cdot u^{*} \cdot d \Omega \cdot d t+\int_{\Gamma} R \cdot u^{*} \cdot d \Gamma \cdot d t
\end{gathered}
$$

In the case of a viscoelastic body $i$, the stress tensor is not only composed by a mechanism storing energy by elasticity responding to the Hooke's law but it is also responding to a second mechanism dissipating energy by viscoelasticity so,

$\sigma^{i}(t)=\sigma^{i}(t)_{e l a}+\sigma^{i}(t)_{v i s c}$

$\boldsymbol{\sigma}^{i}(t)_{\text {Ela }}=\boldsymbol{H}^{i} \cdot \boldsymbol{\varepsilon}_{\text {ela }}^{i}(t)$; Elastic stress

$\boldsymbol{\sigma}^{i}(t)_{v i s c}=\boldsymbol{H}^{i} \cdot \boldsymbol{\varepsilon}_{\text {visc }}^{i}(t)$; Viscoelastic stress

Contrary to elasticity where vibrating energy is stored, damping is a mechanism of energy dissipation. When a body is exposed to external damping sources, it is commonly modeled by the simple memory approach (Rayleight damping) (Osiński 1998). By the other hand, when a structure develops internal friction under a load at a molecular scale, there is a tendency to find new equilibrium positions, this might be caused by inclusions, pores or crystallization. In this case, the vibration characteristic stress may be modeled by a fading memory approach which depends on strain rate. This phenomenon is known as viscoelasticity, a rheological behavior of materials presenting anelastic deformation. Differential models are more commonly used to model viscoelasticity, 
where combinations of uni-dimensional elastic elements and viscous dashpots represent this behavior (Gutierrez-Lemini 2014). This is how there is a linear relation between the stress with its derivatives and strain with its derivatives, the general case with mechanical properties $a$ and $b$ is given by,

$b_{0} \sigma(t)+\sum_{i=1}^{n} b_{i} \frac{d^{i} \sigma(t)}{d t^{i}}=a_{0} \varepsilon(t)+\sum_{i=1}^{m} a_{i} \frac{d^{i} \varepsilon(t)}{d t^{i}}$

A combination of both Kelvin-Voigt model and Maxwell model are more suitable to represent the viscoelastic characteristics of internal friction, including creep, stress relaxation, hysteresis, recovery response and stress dependence on strain rate (Assie et al. 2010). In this sense, the standard linear viscoelastic solid model or simply the Zener model responds to this characteristic. Particularly from assuming that the interfaces are isotropic, with constant Poisson ration and considering only a viscoelastic shear strain, with $n=1$ and $m=1$ and expressing $\tau=\eta / G_{0}$, as the relaxation time, the Zener model now becomes,

$\sigma(t)+\tau \frac{d \sigma(t)}{d t}=G_{0} \varepsilon(t)+G_{\infty} \tau \frac{d \varepsilon(t)}{d t}$.

\subsection{Principle of model reduction}

Nowadays, most of simulation models are implemented with the finite element method. These models, that we could name FE regular models, are highly specialized: one model can only represent the behavior of a unique multilayer structure. Such model is limited in design because some major design parameters are not explicit in the behavioral model such as the number of layers or the constitutive laws of each layer.

We define a FE regular model as:

A finite element regular model can only represent the behavior of a unique multilayer structure: all design parameters must be determined for each simulation (such as the number of layers, the fiber orientation of each layer and the nature of fibers and matrix). A FE regular model is not a parametrized model useful for searching some design solutions (i.e. exploring solution spaces), but rather for validating a design solution.

Definition of a Reduced Model:

In our approach, a reduced model is a model:
- Having a tensorial form,

- Making explicit design variables that are not explicit in a FEM; they are the number of layers, the orthotropic constitutive laws of each layer (including the fiber orientation), and the matrix interface properties (viscosity, thickness). The model becomes a parametrized model,

- Being low computing cost; the size of a model is much lower than a FEM regular model.

A reduced model is useful in exploring solution spaces for defining the main parameters of a composite structure.

\subsection{First numerical approach to make explicit the design parameters, towards a reduced, parametric and multi-scale behavioral model}

We make explicit in our model the design variables determining (Fig. 6):

- The nature of the multi-layer structure : the number of plies,

- The constitutive law of each ply being defined by the usual nine material characteristics for an orthotropic law.

By doing it, we achieve a model that is said:

- Parametrized, making explicit some design parameters,

- Multi-scale because the different design variables address different scales of the composite structure, but together acting on the overall behavior of the structure.

To achieve such parametrized and multi-scale model, we implement a numerical approach based on the variable separation principle. The proper generalized decomposition method (PGD method) has been implemented; it has the advantage to lead, both, to a parametrized model and a to reduced model.

In a laminated composite, the PGD method randomly finds solutions at the meso-scale and then they are tested at the macro-scale until achieving convergence. The PGD implies a separation of space variables and the solution is approximated by a sum of functional products called "modes". For simplicity but without loose of generality, the procedure is

Fig. 6 Lamination model



$$
\begin{aligned}
& m=\text { number of layers }-1 \\
& k=0 ; 1 ; 2 ; \cdots ; m \\
& \mathrm{n}=2 * m+1 \\
& \begin{array}{l}
i=0 ; 1 ; 2 ; \cdots ; n \\
\text { int }_{0} ; \text { int }_{n}={ }^{\text {int }} \\
\text { / } / 2
\end{array}
\end{aligned}
$$


exposed in the case of two dimensions, but similarly more dimensions may be added.

$$
\begin{aligned}
U(x, y) & \cong U^{n}(x, y) \\
U^{n}(x, y) & =\sum_{i=1}^{n}\left\{\begin{array}{l}
X_{\mathrm{u}}^{i} \cdot Y_{\mathrm{u}}^{i} \\
X_{\mathrm{v}}^{i} \cdot Y_{\mathrm{v}}^{i}
\end{array}\right\}
\end{aligned}
$$

In this separated representation, $X$ and $Y$ are functions along each separated domain $x$ and $y$, respectively. The products are performed in each direction $\mathrm{u}$ and $\mathrm{v}$ as shown in Eq. (7). The functions are not needed to be known "a-priori", instead they are constructed from an "alternative direction strategy". This strategy implies that from an initial condition of $(n-1)$ modes already known, the next mode $n$ is obtained by an iteration process such that in iteration $p$ it is possible to compute 1-D $\left\{\begin{array}{l}X_{\mathrm{u}}^{p} \\ X_{\mathrm{v}}^{p}\end{array}\right\}$ vector space from a random guess of functions $\left\{\begin{array}{c}Y_{\mathrm{u}}^{p-1} \\ Y_{\mathrm{v}}^{p-1}\end{array}\right\}$ in a previous iteration $p-1$. So the displacement, strain and test functions are,

$$
\begin{aligned}
& U_{(x, y)}^{n-1, p}=\left(\sum_{i=1}^{n-1}\left\{\begin{array}{l}
X_{\mathrm{u}}^{i} \cdot Y_{\mathrm{u}}^{i} \\
X_{\mathrm{v}}^{i} \cdot Y_{\mathrm{v}}^{i}
\end{array}\right\}\right)+\left\{\begin{array}{l}
X_{\mathrm{u}}^{p} \cdot Y_{\mathrm{u}}^{p-1} \\
X_{\mathrm{v}}^{p} \cdot Y_{\mathrm{v}}^{p-1}
\end{array}\right\} \\
& \boldsymbol{\varepsilon}(n-1, p)=\left(\sum_{i=1}^{n-1}\left\{\begin{array}{l}
\frac{d X_{\mathrm{u}}^{i}}{d x} \cdot Y_{\mathrm{u}}^{i} \\
X_{\mathrm{v}}^{i} \cdot \frac{d Y_{\mathrm{v}}^{i}}{d y} \\
X_{\mathrm{u}}^{i} \cdot \frac{d Y_{\mathrm{u}}^{i}}{d y}+\frac{d X_{\mathrm{v}}^{i}}{d x} \cdot Y_{\mathrm{v}}^{i}
\end{array}\right\}\right) \\
& +\left\{\begin{array}{l}
\frac{d X_{\mathrm{u}}^{p}}{d x} \cdot Y_{\mathrm{u}}^{p-1} \\
X_{\mathrm{v}}^{p} \cdot \frac{d Y_{\mathrm{v}}^{p-1}}{d y} \\
X_{\mathrm{u}}^{p} \cdot \frac{d Y_{\mathrm{u}}^{p-1}}{d y}+\frac{d X_{\mathrm{v}}^{p}}{d x} \cdot Y_{\mathrm{v}}^{p-1}
\end{array}\right\} \\
& \varepsilon^{*}(p-1)=\left\{\begin{array}{l}
\frac{d X_{\mathrm{u}}^{*}}{d x} \cdot Y_{\mathrm{u}}^{p-1} \\
X_{\mathrm{v}}^{*} \cdot \frac{d Y_{\mathrm{v}}^{p-1}}{d y} \\
X_{\mathrm{u}}^{*} \cdot \frac{d Y_{\mathrm{u}}^{p-1}}{d y}+\frac{d X_{\mathrm{v}}^{*}}{d x} \cdot Y_{\mathrm{v}}^{p-1}
\end{array}\right\}
\end{aligned}
$$

Then, from the just computed $\left\{\begin{array}{l}X_{\mathrm{u}}^{p} \\ X_{\mathrm{v}}^{p}\end{array}\right\}$, it is possible to obtain $\left\{\begin{array}{l}Y_{\mathrm{u}}^{p} \\ Y_{\mathrm{v}}^{p}\end{array}\right\}$ in iteration $p$ with displacement and test function

$$
\begin{aligned}
& U_{(x, y)}^{n-1, p}=\left(\sum_{i=1}^{n-1}\left\{\begin{array}{l}
X_{\mathrm{u}}^{i} \cdot Y_{\mathrm{u}}^{i} \\
X_{\mathrm{v}}^{i} \cdot Y_{\mathrm{v}}^{i}
\end{array}\right\}\right)+\left\{\begin{array}{l}
X_{\mathrm{u}}^{p} \cdot Y_{\mathrm{u}}^{p} \\
X_{\mathrm{v}}^{p} \cdot Y_{\mathrm{v}}^{p}
\end{array}\right\} \\
& \varepsilon^{*}(p-1)=\left\{\begin{array}{l}
\frac{d X_{\mathrm{u}}^{p}}{d x} \cdot Y_{\mathrm{u}}^{*} \\
X_{v}^{p} \cdot \frac{d Y_{v}^{*}}{d y} \\
X_{\mathrm{u}}^{p} \cdot \frac{d Y_{\mathrm{u}}^{*}}{d y}+\frac{d X_{\mathrm{v}}^{p}}{d x} \cdot Y_{\mathrm{v}}^{*}
\end{array}\right\}
\end{aligned}
$$

The iteration process stops when the norm $\epsilon_{p}$ of the difference between the obtained mode at iteration $p$ and the last incorporated mode $(n-1)$ is small. Similarly, the aZpproximated solution $U^{n}(x, y)$ is achieved when the sum of all modes results in a sufficiently small residual $\epsilon_{\text {res }}$. As a consequence of the separation of space domains, the number of equations to be solved are $N \times D$ at each iteration, instead of $N^{D}$ as in FEM.

The most remarkable characteristic of the PGD method is the ability to handle parametric computations as a separated extra domain (Chinesta et al. 2014), in such a way rather than a single solution, the method produces a model that allows obtaining solutions within a scenario inside the boundaries of a weight function. This is very different and efficient than other parametric analysis as the Monte Carlo method, where a solution has to be computed several times, each with different input quantities to obtain a set of solutions to fit a model (ElHafidi et al. 2017).

When Eqs. (8), (9) and (10) are implemented on the governing Eq. (3), the orthotropic material properties are introduced according to Table 2, where the bodies $i$ are numbered as indicated in Fig. 6 .

By the other side, the experimental data do not produce detailed information about the viscoelastic properties in the interfaces, only a global idea of the beam viscoelastic behavior was given. Therefore, the four fractional operators in Eq. (13) must be derived from an identification procedure.

\subsection{Second numerical approach: parametrization of fractional operators to represent the damping behavior due to the matrix}

Beyond the Zener model, additional elastic elements and dashpots may be added in more complex models with the intention to gain accuracy; however, experimental results show a weaker frequency dependence than the effect of a viscous dashpot with constant loss factor for all frequencies (Pritz 1996). For this reason, especially in the case of metals and polymers, it is known that viscous friction is not the actual characteristic of their viscoelastic behavior; indeed, there are several research works reporting that the stress in a dashpot representing structural internal friction is not completely related to a derivative of integer order, as it is used in fluids, but instead it could be related in a diminished extent to the time variation of strain or a fractional derivative of the strain. Further, in Pritz (1996), the advantages of assuming a four-parameter Zener model is explained in terms of the satisfaction of the thermodynamic constraints if the order of the derivatives $\alpha=\beta$, and a wider frequency range of application. So Eq. (6) becomes,

$\sigma(t)+\tau^{\alpha} \frac{d^{\alpha} \sigma(t)}{d t^{\alpha}}=G_{0} \varepsilon(t)+G_{\infty} \tau^{\alpha} \frac{d^{\alpha} \varepsilon(t)}{d t^{\alpha}}$. 
Table 2 Mechanical properties

\begin{tabular}{lllll}
\hline & Units & Interface (epoxy) & Ply (fibers) & Layer (fibers + epoxy) \\
\hline $\begin{array}{l}\text { Young's module }\left(\mathrm{E}_{\mathrm{xx}}\right) \\
\text { (principal direction) }\end{array}$ & $\mathrm{GPa}$ & 3.5 & 294 & 170 \\
Young's module $\left(\mathrm{E}_{\mathrm{yy}}\right)$ & $\mathrm{GPa}$ & 3.5 & & \\
Young's module $\left(\mathrm{E}_{\mathrm{zz}}\right)$ & $\mathrm{GPa}$ & 3.5 & 15 & 15 \\
Poisson's ratio $\left(\mathrm{v}_{\mathrm{xy}}\right)$ & - & 0.35 & 15 & 15 \\
Poisson's ratio $\left(\mathrm{v}_{\mathrm{yz}}\right)$ & - & 0.35 & 0.27 & 0.27 \\
Poisson's ratio $\left(\mathrm{v}_{\mathrm{xz}}\right)$ & - & 0.35 & 0.4 & 0.4 \\
Shear modulus $\mathrm{G}_{\mathrm{xy}}$ & $\mathrm{GPa}$ & 1.85 & 0.27 & 0.27 \\
Shear modulus $\mathrm{G}_{\mathrm{yz}}$ & $\mathrm{GPa}$ & 1.85 & 4.8 & 4.8 \\
Shear modulus $\mathrm{G}_{\mathrm{xz}}$ & $\mathrm{GPa}$ & 1.85 & 3.2 & 3.2 \\
Layer thickness & $\mathrm{mm}$ & & 4.8 & 4.8 \\
Total thickness for 8 layers $(h): 1.544 \mathrm{~mm}$ & & & 0.193 \\
Length $(l): 250 \mathrm{~mm}$ & & & \\
Width $(w): 25 \mathrm{~mm}$ & & & \\
Stacking sequence: $[00,90,90,00]_{\mathrm{s}}$ & & & \\
\hline
\end{tabular}

By the Riemann-Liouville, the definition of the fractional operator is (Ostalczyk 2016)

$\frac{d^{\alpha} f(t)}{d t^{\alpha}}=\frac{1}{\Gamma(1-\alpha)} \frac{d}{d t} \int_{0}^{t} \frac{f(s)}{(t-s)^{\alpha}} d s$

where the gamma function $\Gamma$ introduces the memory effect by,

$n !=\Gamma(n+1)$.

In a time integration scheme, the Grünwald approximation to the fractional operator is used instead, with time steps $h=\Delta t$, so that the $w_{j}$ are the non-integer infinite sum of binomial coefficients introducing the memory effect; this may be approximated finite if $h$ is small enough, so the fractional operand develops into,

$$
\begin{aligned}
\frac{d^{\alpha} f(t)}{d t^{\alpha}} & \cong \frac{1}{h^{\alpha}} \sum_{j=0}^{N_{t}} w_{j} f(t-j h) \\
w_{j} & =\frac{\Gamma(j-\alpha)}{\Gamma(-\alpha) \Gamma(j+1)}=\frac{j-(\alpha+1)}{j} w_{j-1} .
\end{aligned}
$$

Finally, using the Grünwald approximation as in Galucio (2004), the viscoelastic shear strain in Eq. (13) in tensor notation for an interface $i$ is,

$$
\begin{aligned}
\boldsymbol{\varepsilon}_{x y \text { visc }}^{i}(t)= & \left(1-\frac{\tau^{\alpha}}{\tau^{\alpha}+\Delta t^{\alpha}}\right) \frac{G_{\infty}-G_{0}}{G_{\infty}} \boldsymbol{\varepsilon}_{x y \text { ela }}(t) \\
& -\frac{\tau^{\alpha}}{\tau^{\alpha}+\Delta t^{\alpha}} \sum_{j=1}^{N_{t}} w_{j} \boldsymbol{\varepsilon}_{x y \text { visc }}^{i}(t-j \Delta t) .
\end{aligned}
$$

It is seen from the equation above that the viscoelastic strain is composed both by an instantaneous effect and a history effect computed at previous time steps so,

$$
\begin{aligned}
\sigma_{x y}^{i}(t)_{v i s c}= & \sigma_{x y}^{i}(t)_{i n s t}+\sigma_{x y}^{i}(t)_{m e m} \\
\sigma_{x y}^{i}(t)_{i n s t}= & 2 G_{0}\left(1+\frac{\tau^{\alpha}}{\tau^{\alpha}+\Delta t^{\alpha}}\right) \\
& \frac{G_{\infty}-G_{0}}{G_{\infty}} \varepsilon_{x y \text { ela }}(t) \text { Instantaneous stress } \\
\sigma_{x y}^{i}(t)_{m e m}= & 2 \frac{G_{\infty}}{G_{0}} \frac{\tau^{\alpha}}{\tau^{\alpha}+\Delta t^{\alpha}} \\
& \sum_{j=1}^{N_{t}} w_{j} \varepsilon_{x y \text { mem }}^{i}(t-j \Delta t) \text { Memory stress }
\end{aligned}
$$

Monte Carlo simulations have been frequently used by different authors to construct models to identify the viscoelastic parameters from experimental FRF measurements (El-Hafidi et al. 2017; Irazu and Elejabarrieta 2017; Zhang et al. 2013). By this way, several discrete simulations are selected with carefully selected points of the parameters to be found, so the solution has to be computed several times. In contrast, the PGD method is able to produce a parametrized model solution incorporating an additional domain for each variable, so they can have a variation within a given probability distribution. An identification algorithm based on a function that minimizes the error between the experimental data and the simulated response may be used, but the main objective of this work is rather to define the methodology to develop parametrized models, so that optimization algorithms may be applied to them in a future work. Therefore, as a first instance it is decided to keep the relaxation time $\tau$ and the 
Table 3 Viscoelastic properties at the interfaces

$$
\begin{aligned}
& \tau=1.031 \times 10^{-7} \mathrm{~s} \\
& \mathrm{G}_{0}=3.24 \times 10^{6} \mathrm{~Pa} \\
& 0 \leq \alpha \leq 1 \\
& 5 \times 10^{7} \mathrm{~Pa} \leq \mathrm{G}_{\infty} \leq 5 \times 10^{9} \mathrm{~Pa}
\end{aligned}
$$

short-term shear modulus $G_{0}$ constant, using the data published in (Irazu and Elejabarrieta 2017) and exploring the best solution making direct variations on the fractional order $\alpha$ and the long-term shear modulus $G_{\infty}$, as shown in Table 3 .

Each domain $x$ and $y$ must be specified separately by a 1-D mesh, which at the same time shall be defined in each direction $\mathrm{u}$ and $\mathrm{v}$, as illustrated in Fig. 7, assuming 2D plane strain.

In this case, incorporating the fractional parameters in Eq. (7) becomes,

$$
\begin{aligned}
& U(x, y) \cong U^{n}(x, y, a, d) \\
& U^{n}(x, y)=\sum_{i=1}^{n}\left\{\begin{array}{l}
X_{\mathrm{u}}^{i} \cdot Y_{\mathrm{u}}^{i} \cdot A_{\mathrm{u}}^{i} \cdot D_{\mathrm{u}}^{i} \\
X_{\mathrm{v}}^{i} \cdot Y_{\mathrm{v}}^{i} \cdot A_{\mathrm{v}}^{i} \cdot D_{\mathrm{v}}^{i}
\end{array}\right\}
\end{aligned}
$$

The approach adopted here is to assume orthotropic elastic plies and isotropic viscoelastic interfaces. To the sake of simplicity plane strain will be assumed so in this case for an orthotropic material the mechanical properties are,

$$
\begin{aligned}
& J=\frac{1}{1-\vartheta_{x y} \vartheta_{y x}} \\
& {\left[H^{i}\right]=J\left[\begin{array}{lcc}
E_{x x} & E_{x x}\left(\vartheta_{y x}\right) & 0 \\
E_{x x}\left(\vartheta_{y x}\right) & E_{y y} & 0 \\
0 & 0 & G_{x y} / J
\end{array}\right]} \\
& m=\text { number of layers }-1 \\
& k=0 ; 1 ; 2 ; \cdots ; m \\
& \mathrm{n}=2 * m+1 \\
& i=0 ; 1 ; 2 ; \cdots ; n \\
& \begin{array}{l}
\text { ply }_{n-1} \\
\text { ply } \\
\text { ply }_{3} \\
\text { ply }
\end{array}
\end{aligned}
$$

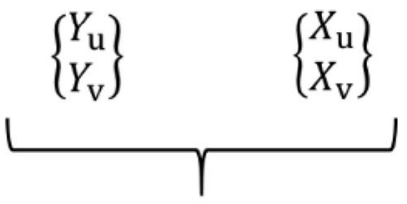

Mechanical properties are first assigned at the layer scale as a discrete function trough the thickness domain $y$, keeping the $x$ domain constant and equal to unity. Just the shear modulus $G_{x y}$ is presented here, but the other properties are handled by the same manner,

$$
\begin{aligned}
& G_{x y}=G_{x u} \cdot\left(G_{y u 0} \cdot G_{q u 0}+\cdots+G_{y u i} \cdot G_{q u i}\right. \\
& \left.+\cdots+G_{y u n} \cdot G_{q u n}\right) \\
& +\left(1+\left(\frac{\tau^{(\alpha)}}{\tau^{(\alpha)}+\Delta t^{(\alpha)}}\right) \frac{G_{y \infty}-G_{y 0}}{G_{y 0}}\right) \\
& G_{x \mathrm{u}}=1 \\
& G_{y \mathrm{u} i}= \begin{cases}G_{x y i} & \text { if } y=\operatorname{bod} y_{i} \\
0 & \text { if } y \neq \operatorname{bod} y_{i}\end{cases} \\
& G_{y \infty}=\left\{\begin{array}{l}
0 \text { if } i \notin \text { interface } \\
d \text { if } i \in \text { interface }
\end{array}\right. \\
& 5 \times 10^{7} P a \leq d \leq 5 \times 10^{9} P a \\
& \alpha_{a \mathrm{u}}=\alpha_{a \mathrm{v}}=\alpha=a ; \quad 0 \leq \mathrm{a} \leq 1
\end{aligned}
$$

It is convenient to group the known terms to the right of the governing equation, so recalling from Eq. (18), it is possible to redefine the load into the beam adding the memory load so,

$$
\begin{aligned}
& R=R_{\text {ext }}+R_{\text {mem }} \\
& R_{\text {ext }}=f_{y}(t) \text { Instantaneous stress } \\
& R_{\text {mem }}=2 \frac{\tau^{\left(\alpha_{a}\right)}}{\tau^{\left(\alpha_{a}\right)}+\Delta t^{\left(\alpha_{a}\right)}} \frac{G_{\infty}}{G_{0}} H_{x y}^{i} \\
& \quad \times \sum_{j=1}^{N_{t}} w_{j} U_{m e m}^{i}(t-j \Delta t) \text { Memory stress }
\end{aligned}
$$

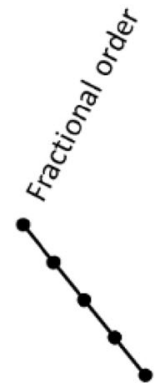

$\left\{\begin{array}{l}A_{\mathrm{u}} \\ A_{\mathrm{v}}\end{array}\right\}$

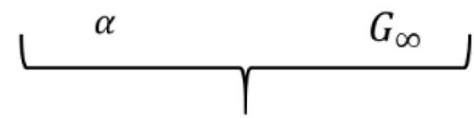

Parametrization of fractional operators



Fig. 7 PGD implementation and fractional operator parametrization 
Summarizing, from Eq. (4),

$\boldsymbol{\sigma}_{x x}=J \cdot\left(E_{x x} \boldsymbol{\varepsilon}_{x x}\left(1-\vartheta_{y z} \vartheta_{z y}\right)+E_{x x} \boldsymbol{\varepsilon}_{y y}\left(\vartheta_{y x}-\vartheta_{z x} \vartheta_{y z}\right)\right)$
$\boldsymbol{\sigma}_{y y}=J\left(E_{y y} \boldsymbol{\varepsilon}_{y y}\left(1-\vartheta_{x z} \vartheta_{z x}\right)+E_{x x} \varepsilon_{x x}\left(\vartheta_{y x}-\vartheta_{z x} \vartheta_{y z}\right)\right)$
$\boldsymbol{\sigma}_{x y}=2 G_{x y} \boldsymbol{\varepsilon}_{x y \text { ela }}+2 G_{x y} \boldsymbol{\varepsilon}_{x y}$ visc

Then the governing Eq. (3) becomes,

$$
\begin{aligned}
& \int_{\Omega} \boldsymbol{\sigma}_{x x} \cdot \boldsymbol{\varepsilon}_{x x}^{*} \cdot d x \cdot d y \cdot d d \cdot d a \cdot d t \\
& \quad+\int_{\Omega} \boldsymbol{\sigma}_{y y} \cdot \boldsymbol{\varepsilon}_{y y}^{*} \cdot d x \cdot d y \cdot d d \cdot d a \cdot d t \\
& \quad+\int_{\Omega} \boldsymbol{\sigma}_{x y} \cdot 2 \boldsymbol{\varepsilon}_{x y}^{*} \cdot d x \cdot d y \cdot d d \cdot d a \cdot d t \\
& \quad-\rho \int_{\Omega} \frac{\partial^{2} U^{i}}{\partial t^{2}} \cdot u^{*} \cdot d x \cdot d y \cdot \\
& d t=\int_{\Gamma} R \cdot u^{*} \cdot d \Gamma \cdot d d \cdot d a \cdot d t
\end{aligned}
$$

Incorporating domains $d$ and a in Eqs. (9) and (10) and applying these to Eq. (24),

$$
\begin{aligned}
& \boldsymbol{\sigma}_{x x} \cdot \boldsymbol{\varepsilon}_{x x}^{*}=J \cdot\left(E _ { x x } \left(\left(\sum_{i=1}^{n-1}\left(\frac{d X_{\mathrm{u}}^{i}}{d x}\right) \cdot Y_{\mathrm{u}}^{i} \cdot D_{\mathrm{u}}^{i} \cdot A_{\mathrm{u}}^{i}\right)\right.\right. \\
& \left.+\left(\frac{d X_{\mathrm{u}}^{p}}{d x}\right) \cdot Y_{\mathrm{u}}^{p-1} \cdot D_{\mathrm{u}}^{p-1} \cdot A_{\mathrm{u}}^{p-1}\right)\left(1-\vartheta_{y z} \vartheta_{z y}\right) \\
& +E_{x x}\left(\left(\sum_{i=1}^{n-1} X_{\mathrm{v}}^{i}\left(\frac{d Y_{\mathrm{v}}^{i}}{d y}\right) \cdot D_{\mathrm{v}}^{i} \cdot A_{\mathrm{v}}^{i}\right)\right. \\
& \left.+X_{\mathrm{v}}^{p} \cdot\left(\frac{d Y_{\mathrm{v}}^{p-1}}{d y}\right) \cdot D_{\mathrm{v}}^{p-1} \cdot A_{\mathrm{v}}^{p-1}\left(\vartheta_{y x}-\vartheta_{z x} \vartheta_{y z}\right)\right) \\
& \cdot\left(\frac{d X_{\mathrm{u}}^{*}}{d x}\right) \cdot Y_{\mathrm{u}}^{p-1} \cdot D_{\mathrm{u}}^{p-1} \cdot A_{\mathrm{u}} p-1 \\
& \boldsymbol{\sigma}_{y y} \cdot \boldsymbol{\varepsilon}_{y y}^{*}=J \cdot\left(E _ { y y } \left(\left(\sum_{i=1}^{n-1} X_{\mathrm{v}}^{i}\left(\frac{d Y_{\mathrm{v}}^{i}}{d y}\right) \cdot D_{\mathrm{v}}^{i} \cdot A_{\mathrm{v}}^{i}\right)\right.\right. \\
& +X_{\mathrm{v}}^{p} \cdot\left(\frac{d Y_{\mathrm{v}}^{p-1}}{d y}\right) \cdot D_{\mathrm{v}}^{p-1} \cdot A_{\mathrm{v}}^{p-1}\left(1-\vartheta_{y z} \vartheta_{z y}\right) \\
& +E_{x x}\left(\left(\sum_{i=1}^{n-1}\left(\frac{d X_{\mathrm{u}}^{i}}{d x}\right) \cdot Y_{\mathrm{u}}^{i} \cdot D_{\mathrm{u}}^{i} \cdot A_{\mathrm{u}}^{i}\right)\right. \\
& \left.\left.+\left(\frac{d X_{\mathrm{u}}^{p}}{d x}\right) \cdot Y_{\mathrm{u}}^{p-1} \cdot D_{\mathrm{u}}^{p-1} \cdot A_{\mathrm{u}}^{p-1}\right)\left(\vartheta_{y x}-\vartheta_{z x} \vartheta_{y z}\right)\right) \\
& \cdot X_{\mathrm{v}}^{*} \cdot\left(\frac{d Y_{\mathrm{v}}^{p-1}}{d y}\right) \cdot D_{\mathrm{v}}^{p-1} \cdot A_{\mathrm{v}}^{p-1} \\
& \sigma_{x y} \cdot 2 \boldsymbol{\varepsilon}_{x y}^{*}=\left(G _ { x y } \left(\left(\sum _ { i = 1 } ^ { n - 1 } \left(X_{\mathrm{u}}^{i} \cdot \frac{d Y_{\mathrm{u}}^{i}}{d y} \cdot D_{\mathrm{u}}^{i} \cdot A_{\mathrm{u}}^{i}\right.\right.\right.\right. \\
& \left.\left.+\frac{d X_{\mathrm{v}}^{i}}{d x} \cdot Y_{\mathrm{v}}^{i} \cdot D_{\mathrm{v}}^{i} \cdot A_{\mathrm{v}}^{i}+2 G_{x y} \boldsymbol{\varepsilon}_{x y \text { visc }} \cdot D_{\mathrm{v}}^{i} \cdot A_{\mathrm{v}}^{i}\right)\right) \\
& +X_{\mathrm{u}}^{p} \cdot \frac{d Y_{\mathrm{u}}^{p-1}}{d y} \cdot D_{\mathrm{u}}^{p-1} \cdot A_{\mathrm{u}}^{p-1}+\frac{d X_{\mathrm{v}}^{p}}{d x} \cdot Y_{\mathrm{v}}^{p-1} \cdot D_{\mathrm{v}}^{p-1}
\end{aligned}
$$

$$
\begin{aligned}
& \left.\left.\cdot A_{\mathrm{v}}^{p-1}+2 G_{x y} \varepsilon_{x y} v i s c \cdot D_{\mathrm{v}}^{p-1} \cdot A_{\mathrm{v}}^{p-1}\right)\right) \\
& \cdot\left(X_{\mathrm{u}}^{*} \cdot\left(\frac{d Y_{\mathrm{u}}^{p-1}}{d y}\right) \cdot D_{\mathrm{u}}^{p-1} \cdot A_{\mathrm{u}}^{p-1}\right. \\
& \left.+\left(\frac{d X_{\mathrm{v}}^{*}}{d y}\right) \cdot Y_{\mathrm{v}}^{p-1} \cdot D_{\mathrm{v}}^{p-1} \cdot A_{\mathrm{v}}^{p-1}\right) \\
R= & f_{y}(t) \cdot X_{\mathrm{v}}^{*} \cdot\left(\frac{d Y_{\mathrm{v}}^{p-1}}{d y}\right) \cdot D_{\mathrm{v}}^{p-1} \cdot A_{\mathrm{v}}^{p-1}
\end{aligned}
$$

A final important step is to reorganize Eq. (25) such that the domain $x$ is apart from the domain $y$ and the unknowns remain at the left part of the equation. Finally, after converging to a solution, from the $1 \mathrm{D}$ solutions a new solution is mapped in 2D to the $y$ direction and another one to the $x$ direction. Then in Fenics, the 2D solution may be projected either to separated 2D function spaces or combine them to a $2 \mathrm{D}$ vector function space.

\subsection{Combining numerical approach to an experimental process to identify damping Parameters}

Using the same setup shown in Fig. 3, two sinusoidal excitation forces were generated with a maximum amplitude of $1 \mathrm{~N}$. The frequencies were $50 \mathrm{~Hz}$ and $120 \mathrm{~Hz}$, so they are apart from the resonances. The responses were passed through a high pass filter with cut frequency on $10 \mathrm{~Hz}$. To compare the results, the simulated data were first synchronized having as reference the excitation force.

\section{Identification procedure}

Recalling that only the long-term relaxation module $G_{\infty}$ and the fractional order derivative $\alpha$ were parametrized, a quick simple direct search over the solution scenario generated by the PGD method was performed, so that first $G_{\infty}$ was adjusted against the response amplitude with $50 \mathrm{~Hz}$ excitation and fixing $\alpha=0.9$. Then $\alpha$ was adjusted against the response amplitude with $120 \mathrm{~Hz}$ excitation. This identification is done on post-processing; the computing cost is very low since technically these are arrays projected on 2D FEM meshes. Some of the values used are presented in Table 4, and the results are presented in Fig. 8.

As expected, adjusting the long-term shear modulus lags the simulated response at $50 \mathrm{~Hz}$; however, the results above show a better fit at $120 \mathrm{~Hz}$ if the loss factor is not related to an integer order of the strain derivative as it is in the classic Zener's model, but to a derivative of diminished order, this trend agrees with the ones analyzed in the references. The data fit may be improved by incorporating the relaxation time to the PGD reduced model and using an optimization algorithm that minimizes the error, with the advantage that every 
Table 4 Fractional parameter identification

\begin{tabular}{lllll}
\hline & $50 \mathrm{~Hz}$ & $120 \mathrm{~Hz}$ \\
\hline$G_{\infty}[\mathrm{Pa}]$ & $d 1=1 \times 10^{8}$ & $d 2=6 \times 10^{8}$ & $d 3=7,1 \times 10^{8}$ & $d 3=7,1 \times 10^{8}$ \\
$\alpha$ & $a 1=0.9$ & & $a 1=0.9 \quad a 2=0.63$ \\
\hline
\end{tabular}
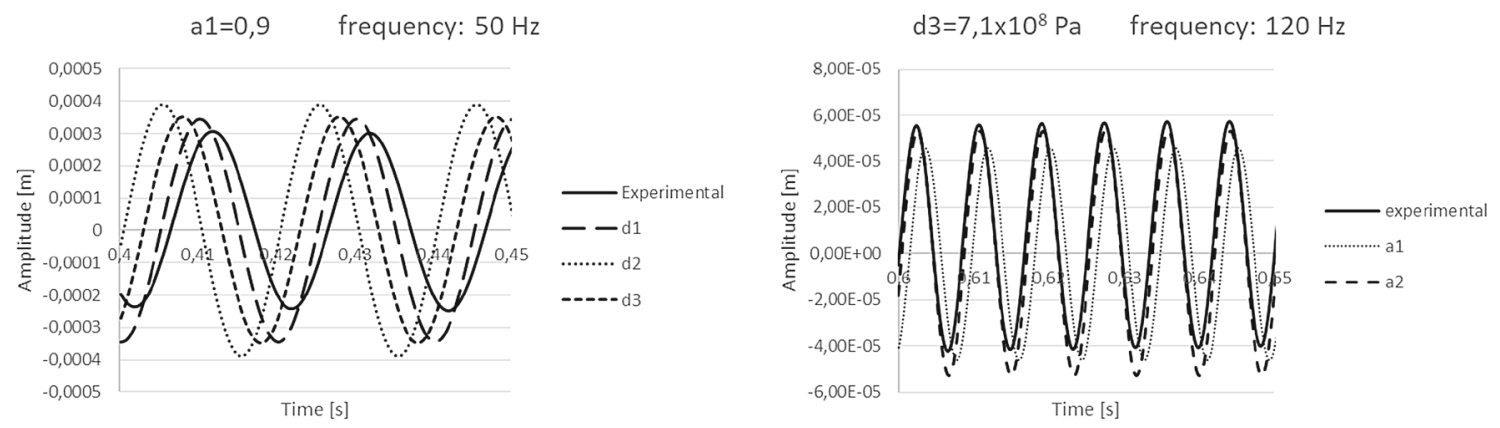

Fig. 8 Fractional parameters adjustment. Left: adjusting $G_{\infty}$ with $50 \mathrm{~Hz}$ excitation force. Right: adjusting $\alpha$ with $120 \mathrm{~Hz}$ excitation force

computed solution may be quickly calculated with light computing resources.

\section{A multi-scale, reduced and parametrized model for fast simulation in CAE}

\subsection{A parametrized model of the dynamic behavior of composite beam}

We propose a reduced model making explicit the main design parameters of the laminated beam even if these parameters occurs at different scales. Figure 9 presents:

- these design parameters,

- the variables allowing to know the overall behavior of the laminated beam.

\subsection{A separated and reduced model of the dynamic behavior of composite beam}

The application of the PGD method adds the required dimensions. In this case, the displacement field is,

$$
\begin{aligned}
& U(x, y) \cong U^{n}(x, y, q, s, p, m) \\
& U^{n}(x, y)=\sum_{i=1}^{n}\left\{\begin{array}{l}
X_{\mathrm{u}}^{i} \cdot Y_{\mathrm{u}}^{i} \cdot Q_{\mathrm{u}}^{i} \cdot S_{\mathrm{u}}^{i} \cdot P_{\mathrm{u}}^{i} \cdot M_{\mathrm{u}}^{i} \\
X_{\mathrm{v}}^{i} \cdot Y_{\mathrm{v}}^{i} \cdot Q_{\mathrm{v}}^{i} \cdot S_{\mathrm{v}}^{i} \cdot P_{\mathrm{v}}^{i} \cdot M_{\mathrm{v}}^{i}
\end{array}\right\}
\end{aligned}
$$

To the sake of simplicity, in this work the model is limited to symmetrical plies orientation; additionally, the plies are grouped as shown in Fig. 10 so they can be treated individually by coefficients on the appropriate dimension domain, thus computing individual stresses needs grouping the properties as shown in Fig. 10 for the Young's modulus.
Under this circumstances, the Young modulus is expressed by,

$$
\begin{aligned}
E_{x x}^{i}= & E_{x \mathrm{u}} \cdot E_{y \mathrm{u}}^{i} \cdot E_{q \mathrm{u}}^{i} \cdot E_{s \mathrm{u}}^{i} \cdot E_{p \mathrm{u}}^{i} \cdot E_{m \mathrm{u}}^{i} \\
E_{x \mathrm{u}}= & 1 \text { Material properties direction u through domain } x \\
E_{y \mathrm{u}}^{i}= & \begin{cases}E_{x x}^{i} & \text { if } y=b o d y_{i} \\
0 & \text { if } y \neq b o d y_{i}\end{cases} \\
& \text { material properties direction u through domain } y \\
E_{q u}^{i}= & \begin{cases}q & \text { if } y=b o d y_{i} \\
1 & \text { if } y \neq \operatorname{bod} y_{i}\end{cases} \\
& \text { Variation of material properties } \\
E_{s \mathrm{u}}^{i}= & \begin{cases}\cos \left(\theta_{s}\right)+\frac{E_{z z}^{i}}{E_{x x}^{i}} \sin \left(\theta_{s}\right) & \text { bod } y_{i} \in \operatorname{group} V 1 \\
1 & \text { if bod } y_{i} \notin \operatorname{group} V 1\end{cases}
\end{aligned}
$$

Ply orientation of group V1

$$
E_{p \mathrm{u}}^{i}= \begin{cases}\cos \left(\theta_{p}\right)+\frac{E_{z z}^{i}}{E_{x x}^{i}} \sin \left(\theta_{p}\right) & \text { if bod } y_{i} \in \text { group } V 2 \\ x 1 & \text { if bod } y_{i} \notin \text { group } V 2\end{cases}
$$

Ply orientation of group V2

$$
E_{m \mathrm{u} 1}^{i}=\left\{\begin{array}{l}
1 \times 10^{-14} \text { otherwise } \\
1 \text { if } m \geq 8
\end{array}\right.
$$$$
\text { Presence of group V1 }
$$

$E_{m \mathrm{u} 2}^{i}=\left\{\begin{array}{l}1 \times 10^{-14} \text { otherwise } \\ 1 \text { if } m \geq 6\end{array}\right.$ Presence of group V2.

\subsection{Model processing for CAE}

First, we developed a finite element model to simulate the dynamic behavior of our laminated beam.

The FEM models has been realized with Ansys ${ }^{\circledR}$ by implementing a distributed parallel process. Figure 11 


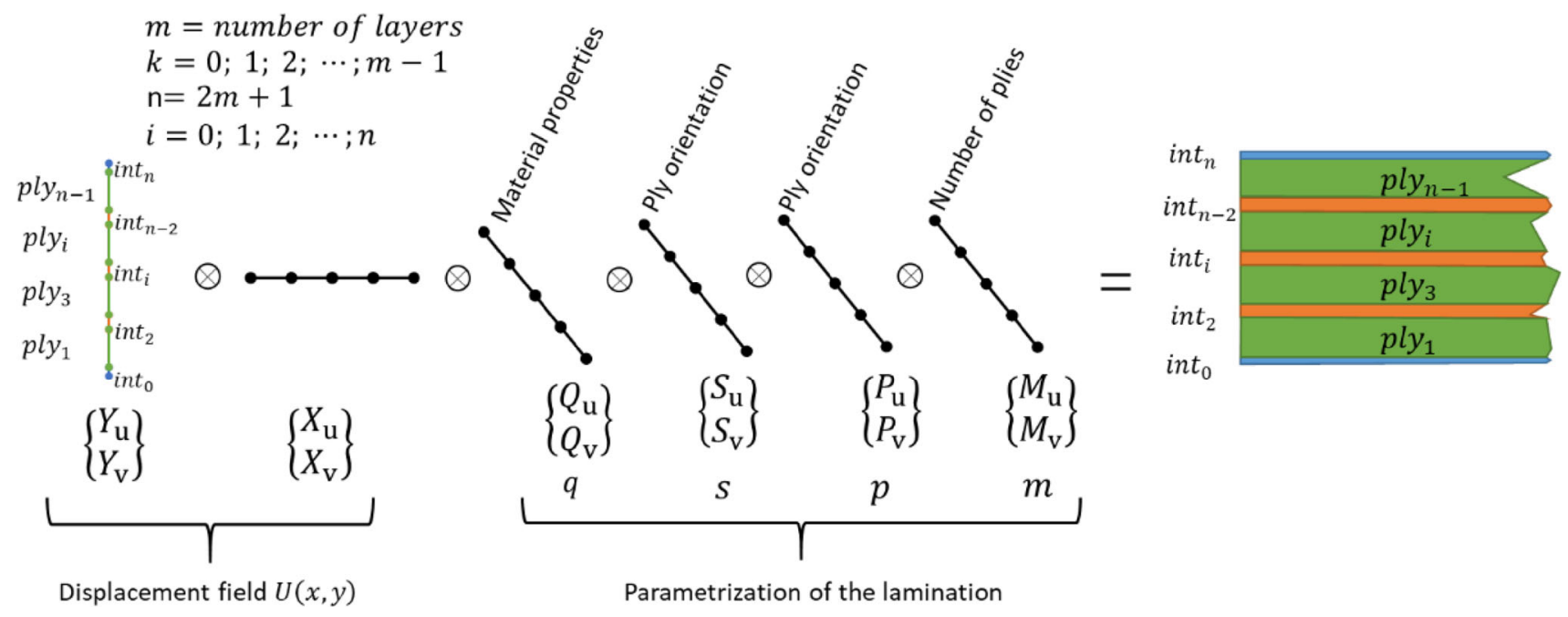

Fig. 9 Design variables of the lamination model

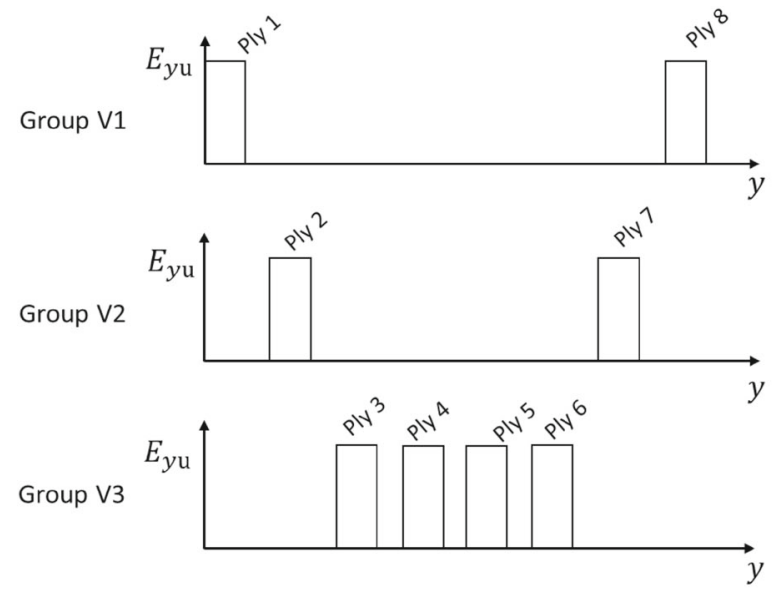

Properties of plies


Properties of interphases

Fig. 10 Grouping of plies

presents the different models being developed, the cost processing, and the advantages and inconvenient.

We realize (Fig. 11):

1 Overall orthotropic models with 3D elements and next with 2D elements : such models and not separated and cannot allow the user to represent the damping effect at interfaces level,

2 Separated models:

- Separately representing the behavior of each ply: each ply is a 2D plane,

- Representing the behavior of the matrix between the plies: the matrix is represented by $2 \mathrm{D}$ planes also having capacities of viscoelasticity,

We were not able to compute a FEM viscoelastic separated model with more than two plies. Figure 11 shows that two plies and one interface is computed in $88 \mathrm{~h}$.
Second, we used our reduced and parametrized model. Table 5 compares the processing cost from the two-plylaminated beam having a viscoelastic behavior. The models were implemented on:

- For the FEM with an Intel® Xeon ${ }^{\circledR}$ CPU @ $2.5 \mathrm{GHz}, 2$ processors, 16 cores, Ram memory: $40 \mathrm{~GB}$, with a parallel processes,

- For the separated and parametrized model on an Intel® core 17 processor, 4 cores. Ram memory 16 GB, without any parallel processes.

As an illustration, we used our reduced and parametrized model to simulate a laminated composite beam having more than two plies: our model is not limited. Figure 12 shows the detail of the shear strain distribution through the thickness direction in a eight-ply beam. The simulation was computed 


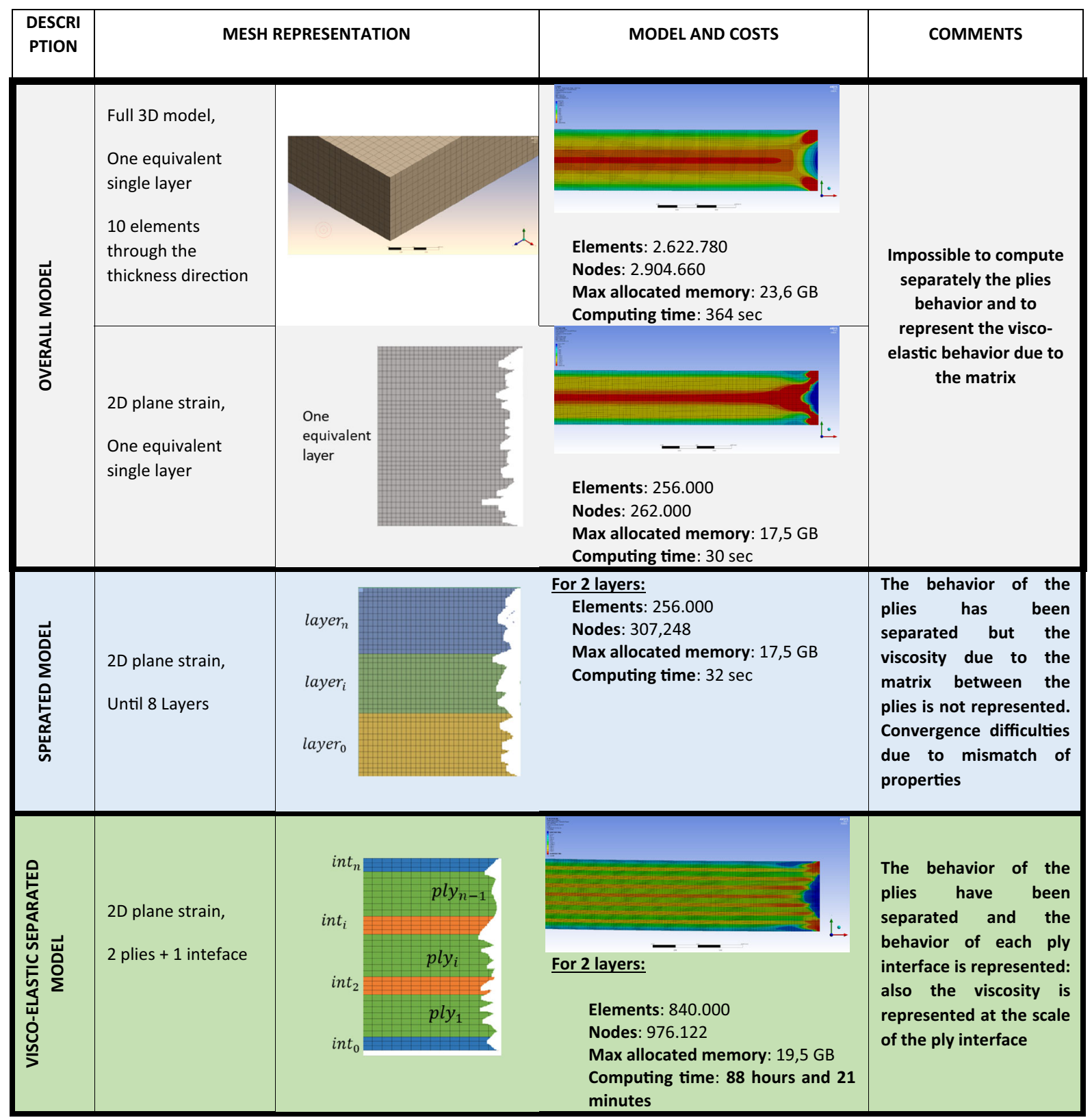

Fig. 11 FEMs being developed

Table 5 Comparing FEM and the reduced model of the two-ply-laminated beam having a viscoelastic behavior

\begin{tabular}{|c|c|c|c|c|c|}
\hline & \multicolumn{2}{|l|}{ FEM } & \multicolumn{2}{|c|}{$\begin{array}{l}\text { Reduced and parametrized } \\
\text { viscoelastic model }\end{array}$} & \multirow[t]{3}{*}{ Error } \\
\hline & \multicolumn{2}{|c|}{ Machine: server distributed processes: 16} & \multicolumn{2}{|c|}{ Machine: laptop no distributed processes } & \\
\hline & Max shear strain $(\%)$ & Computing time & Max shear strain $(\%)$ & Post-processing time & \\
\hline Number of layers:2 Stacking sequence: $[90,00,]^{*}$ & $4.83 \times 10^{-5}$ & $71 \mathrm{~h}$ & $4.55 \times 10^{-5}$ & $15 \mathrm{~s}$ & $5.8 \%$ \\
\hline
\end{tabular}




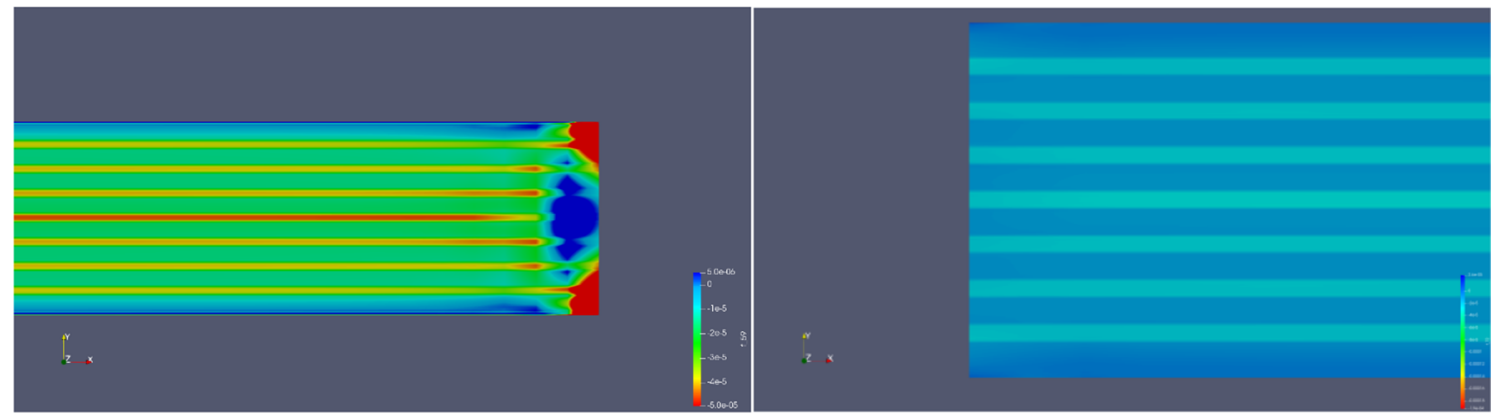

Fig. 12 Shear strain distribution through the thickness direction

in a couple of seconds. An equivalent result was attempted to be run using FEM, but it was impossible to run an explicit and non-linear model with more than two layers on the available computer resources.

\section{Conclusion}

Viscoelastic behavior was detected in laminated composite beams through experimental measurements, particularly observing the phase shift as function of frequency on mobility and stiffness frequency response functions. The viscoelastic characteristic was assumed to be on the interfaces between plies, whereas the fibers were considered responding with an elastic characteristic. Therefore, the Zener model was used to represent the viscoelastic characteristic of the interfaces, but it was found that modifying its derivatives by derivatives of fractional order, the model becomes more feasible to fit experimental measurements. The implementation of fractional derivatives implied the use of a discrete version of the fading memory effect, characteristic of viscoelasticity, so that it could be applied to the Newton-Raphson time integration scheme. The PGD method was used to solve the governing equations at each time step, this is how models were developed, including the parametrization of the fractional order derivative, the long-term shear stress modulus, the variation of material properties, the orientation of groups of plies and of the number of plies.

Computationally speaking, these models are multidimensional arrays so finding particular solutions does not imply a high-computational cost; therefore, the implementation of optimization algorithms reaches faster results.

\section{References}

Ammar A, Zghal A, Morel F, Chinesta F (2015) On the space-time separated representation of integral linear viscoelastic models. Comptes Rendus Mécanique. 343:247-263. https://doi.org/10. 1016/j.crme.2015.02.002
Assie AE, Eltaher MA, Mahmoud FF (2010) Modeling of viscoelastic contact-impact problems. Appl Math Model 34:2336-2352. https://doi.org/10.1016/j.apm.2009.11.001

Bognet B, Bordeu F, Chinesta F, Leygue A, Poitou A (2012) Advanced simulation of models defined in plate geometries: 3D solutions with 2D computational complexity. Comput Methods Appl Mech Eng 201-204:1-12. https://doi.org/10.1016/j.cma.2011.08.025

Budiman BA, Takahashi K, Inaba K, Kishimoto K (2015) A new method of evaluating interfacial properties of a fiber/matrix composite. J Compos Mater 49:465-475. https://doi.org/10.1177/ 0021998314521061

Carrera E (2002) Theories and finite elements for multilayered, anisotropic, composite plates and shells. Arch Comput Methods Eng 9:87-140. https://doi.org/10.1007/BF02736649

Carrera E, Ciuffreda A (2005) A unified formulation to assess theories of multilayered plates for various bending problems. Compos Struct 69:271-293. https://doi.org/10.1016/j.compstruct.2004.07.003

Chinesta F, Keunings R, Leygue A (2014) The proper generalized decomposition for advanced numerical simulations. Springer International Publishing, Cham

Datta P, Ray MC (2016) Finite element analysis of laminated composite plates using zeroth-order shear deformation theory. Int J Mech Mater Des 12:387-400. https://doi.org/10.1007/s10999015-9307-0

El-Hafidi A, Gning PB, Piezel B, Belaïd M, Fontaine S (2017) Determination of dynamic properties of flax fibres reinforced laminate using vibration measurements. Polym Test 57:219-225. https:// doi.org/10.1016/j.polymertesting.2016.11.035

Galucio AC, Deü J-F, Ohayon R (2004) Finite element formulation of viscoelastic sandwich beams using fractional derivative operators. Comput Mech 33:282-291. https://doi.org/10.1007/s00466-0030529-x

Galuppi L, Royer-Carfagni G (2012) Laminated beams with viscoelastic interlayer. Int J Solids Struct 49:2637-2645. https://doi.org/10. 1016/j.ijsolstr.2012.05.028

Ghnatios C, Abisset-Chavanne E, Binetruy C, Chinesta F, Advani S (2016) 3D modeling of squeeze flow of multiaxial laminates. J Non-Newton Fluid Mech 234:188-200. https://doi.org/10.1016/j. jnnfm.2016.06.004

Gutierrez-Lemini D (2014) Engineering viscoelasticity. Springer, New York

Irazu L, Elejabarrieta MJ (2017) The effect of the viscoelastic film and metallic skin on the dynamic properties of thin sandwich structures. Compos Struct 176:407-419. https://doi.org/10.1016/ j.compstruct.2017.05.038

ISO: ISO 7626-2 Vibration and shock - Experimental determination of mechanical mobility - Part 2: Measurements using single-point translation excitation with an attached vibration exciter (1990)

Li J, Huo Q, Li X, Kong X, Wu W (2014) Vibration analyses of laminated composite beams using refined higher-order shear defor- 
mation theory. Int J Mech Mater Des 10:43-52. https://doi.org/10. 1007/s10999-013-9229-7

Lisandrin Paolo, van Tooren Michel (2006) High-order finite elements reduced models for modal analysis of stiffened panels. Int J Mech Materials Des 3(2):111-127. https://doi.org/10.1007/ s10999-006-9017-8

Liu PF, Gu ZP, Peng XQ (2016) A nonlinear cohesive/friction coupled model for shear induced delamination of adhesive composite joint. Int J Fract 199:135-156. https://doi.org/10.1007/s10704016-0100-3

Osiński Z (ed) (1998) Damping of vibrations. Balkema, Rotterdam

Ostalczyk P (2016) Discrete fractional calculus: applications in control and image processing. World Scientific, New Jersey

Pritz T (1996) Analysis of four-parameter fractional derivative model of real solid materials. J Sound Vib 195:103-115. https://doi.org/ 10.1006/jsvi.1996.0406

Reddy JN (1993) An evaluation of equivalent-single-layer and layerwise theories of composite laminates. Compos Struct 25:21-35. https://doi.org/10.1016/0263-8223(93)90147-I
Robbins DH, Reddy JN, Rostam-Abadi F (2005) Layerwise modeling of progressive damage in fiber-reinforced composite laminates. Int $\mathrm{J}$ Mech Mater Des 2:165-182. https://doi.org/10.1007/s10999-0069001-3

Sahoo SR, Ray MC (2017) Analysis of smart damping of laminated composite beams using mesh free method, Int J Mech Materials Des. https://doi.org/10.1007/s10999-017-9379-0

Venkatachalam R, Balasivanandha Prabu S (2012) Vibration and damping analysis of orthotropic sandwich shaft-disc system using finite element method. Int J Mech Materials Des 8(3):287-296. https:// doi.org/10.1007/s10999-012-9195-5

Zhang E, Chazot JD, Antoni J, Hamdi M (2013) Bayesian characterization of Young's modulus of viscoelastic materials in laminated structures. J Sound Vib 332:3654-3666. https://doi.org/10.1016/ j.jsv.2013.02.032

Publisher's Note Springer Nature remains neutral with regard to jurisdictional claims in published maps and institutional affiliations. 